\title{
Treatment resistant depression: causes and consequences
}

The Joint winners of the second Merck Eseoy Prize for 1994 were Drs Andrew Smith and Swaran Singh. Ther essays are published below. The number of entries was 15.

Affective disorder has traditionally been considered as having a good outcome. We concetve of a disease where periodic disturbance is followed by complete remission; this arises from Kraepelin's distinction between dementia praecox (poor prognosis) and affective psychoses (good prognosis). This is an erroneous concept as depression has a poor outcome in many instances (Lee \& Murray, 1988; Kiloh et al, 1988).

Poor outcome suggests a degree of treatment resistance. There are no accepted criteria for this and arbitrary definitions are made. Treatment resistance has been defined as "unsuccessful treatment with at least two antidepressants and/or a course of ECT (Remick, 1989). This implies that at least some therapeutic manoeuvre has been attempted; it differs from 'chronic depression' where therapy has not necessarily been tried. Remick also suggests that 'double depression' (dysthymia and depression) should not be included as their apparent partial response will blur the issue. Scott (1992) defines chronic depression as isymptomatic non-recovery for a period of two years', but adds the proviso that $30 \%$ of these patients have been inadequately or inappropriately treated. Treatment resistant depression and chronic depression are not therefore synonymous. A pragmatic approach involves examination of why apparently depressed patients do not respond to traditional antidepressant therapy. To determine the causes of treatment resistance we can adopt four strategies: 1) acceptance of misdiagnosis and disorders that mimic depression; 2) consideration of prospective studies of depression to determine differences between treatment responstve and treatment resistant subjects; 3) evaluation of patient characteristics in samples of treatment resistant subjects; 4) reasoned inference from augmentation strategles used in treatment resistant groups.

\section{The problem of misdiagnosis}

There are numerous medical and psychiatric disorders that can present with mood disorders. These would not normally be expected to respond to antidepressant medication. They have been reviewed elsewhere (Levine, 1986) and include endocrine, neoplastic and druginduced mood disorders.

\section{Prospective studies of depresalve illness}

There are now an increasing number of studies that describe the natural history of depression (Lee \& Murray, 1988; Kiloh et al, 1988; Coryell et al, 1991; Winokur et al, 1993). We have to assume compliance with treatment to make any meaningful sense of them. The National Institute of Mental Health (NIMH) Study (Winokur et al, 1993) allows delineation of the problem; approximately $20 \%$ of patients at two years and $10 \%$ at five years remained unwell despite adequate treatment with antidepressants (in excess of $200 \mathrm{mg} /$ day of imipramine or $60 \mathrm{mg} /$ day of phenelzine). Failure to respond was found to be independent of age, number of previous episodes, family history and symptom type. Women outnumbered men at all assessment points although the ratio between the sexes did not alter.

It might be reasonable to assume that the factors preventing response to treatment are also responstble for the long-term maintenance of the disorder when no treatment is given, as depression will eventually resolve on its own. Parker et al (1986) followed a cohort of untreated depressives in a primary care setting. Again age, sex and personality factors were not predictive of outcome. Lower social class, better family support and resolution of life events led to a more favourable outcome. Those with younger children and married 
subjects were less likely to recover. The relevance of life events has been repeated elsewhere (Mann et al, 1981; Tennant et al, 1981) and the suggestion is that vulnerability factors for depressive illness - three or more children under 14, lack of confiding relationships, unemployment and early maternal loss (Brown \& Harris, 1981)-actually act as 'propagating factors in depresstve illness. Their typical unresponsive depresstve patient was a woman in a dysfunctional marital relationship, with young children and poor social support. The hypothesis must be that these factors are also important in propagating depression where treatment fails.

Although the NIMH study found no correlation of treatment resistance with age, it is apparent when comparing across studies that those over 65 years of age do a lot worse. Up to $66 \%$ of elderly patients fail to respond to firstline antidepressant treatment (Millard, 1983). The seriousness of this has been disputed (Meats et al, 1991) but it fits with general clinical impressions. Whether the difference in the elderly is due to the ageing brain is unclear; it may be due to the concurrence of chronic lllness, drugs or life events, e.g. retirement and bereavement.

The presence of other psychiatric disorders adversely affects response to treatment. In primary care mixed anxiety-depression has a worse outcome than depression alone (Ormel et al, 1993). Depression in schizophrenia is viewed as integral to that disorder and responstve to neuroleptics (Johnson, 1984).

\section{Characteristics of treatment resistant groups}

Despite evidence of treatment resistance occurring in a substantial minority of depressed patients, there is surprisingly little work that has looked at this group directly.

Remick (1989) considered a group of 114 treatment resistant depressives using his earlier mentioned definition. On the whole they tended to have a longer depresstve episode, concurrent medical problems, personality problems and/or substance misuse. Scott (1992) proposed there were three groups, determined by cluster analysis and not necessarily stable. of patients falling to respond to six weeks' antidepressant therapy; first, a group distinguished by a higher number of suicide attempts (felt to be artefactual); second, a predominately female group with early onset; and third, a later onset group who had more psychotic symptoms. These groups differed in their outcome and factors which inhibited a subsequent recovery were length of episode, the development of psychotic symptoms and comorbidity with a major physical disorder.

Scott (1992) also looked at the characteristics of treatment resistant depressives compared with treatment responstve patients and found them to have higher premorbid neuroticism scores, more previous eplsodes and hospital admissions, a higher familial loading, more frequent use of lithium and more life events after episode onset. When followed up (Scott et al, 1992) two non-lllness factors were important in non-response: first, the length of time for a recognised antidepressant to be prescribed after the onset of the episode; and second, the presence of premorbid neurotic traits. There have been numerous suggestions about how personality and depression interact, but a major methodological problem exists in determining personality traits when the patient is depressed. Two personality types have been hypothesised: i) the highly sociotropic individual who is prone to depression as a result of interpersonal loss; and ii) the highly autonomous individual for whom percetved life failures lead to depression (Joyce, 1994).

\section{Inference from treatment strategies}

The treatment of resistant depression has been well reviewed (Newman \& Janicak, 1991). Assumptions made on the basis of treatment strategles have to be cautious as psychotropic medication is not specific; antidepressants, for example, have anxiolytic properties. However the successful use of drugs known to affect mood in treatment resistant depressives enhances the probability that treatment resistant depression is part of the spectrum of affective disorder.

The most widely used drug is lithium. It has been suggested that lithium's effects are mediated through 5-HT function and that this corresponds with clinical outcome (Cowen et al, 1991). There appears to be no optimal serum level for response (Dinan, 1994). Electroconvulsive therapy, thyroid hormones and atypical antidepressant have all been used with varying degrees of success.

So where does this leave us? It appears that treatment resistant depression forms a subgroup of depressed patients and that the two are nosologically linked. The differences between the two groups are less apparent. Some 
of the factors of the resistant group are purely descriptive (such as higher use of lithium in the past), while others may be important in the genesis of the disorder (such as life events and personality). Apart from the elderly having a higher incidence there is no correlation with age within a general adult population. Gender, family history and symptom type appear unimportant, though the latter, if severe, probably causes prompter treatment. Factors predisposing to the development of resistant depression include lack of prompt treatment in the acute illness, persistent lack of social support, presence of life stressors, chronic physical ailments or psychiatric disorders and substance abuse. Personality factors are important as they provide the background and template to the mood change. The hypothesis that vulnerable personality types (sociotropy and autonomy) exdst appears entirely plausible.

There is evidence to suggest the disorder may fit a medical model when subsequent response to treatment is considered; however, psychological and social factors are clearly involved. That lack of response is directly related to hesitancy of treatment in the acute phase may act at various levels: biological (through change in neurotransmitters), psychological (through reinforcement by cognitive or behavioural means) or social (preventing resolution of life events). A model combining these is proposed by Ormel et al (1993). The 'dynamic-equilibrium model' proposes that symptom levels are deflected (in this case elevated) by persistent life events and poor coping strategies including substance abuse.

Not surprisingly the lack of direct data on treatment resistant groups prohibits an accurate prediction of their outcome. As much as previous illness characteristics predict the future it is fair to suggest that these patients can expect a poor outcome. While this is true in reality, it is clear that this could be vastly improved.

The NIMH study showed that the treatment resistant depressive patients had a $50 \%$ chance of subsequently recovering with three years' follow-up. Where active, directed therapy has been undertaken and the results are generally encouraging. Remick (1989) found that absolute treatment resistance is rare, as $60 \%$ of his group achieved complete remission with multimodel therapy. Scott (1992) found that $75 \%$ would achieve remission at some stage. However only $42 \%$ were well at the end of four years follow-up. Treatment resistance is not therefore an 'end-point'; it should inspire the clinician to consider augmentation or alternattve treatments. Reluctance to do so only compounds the problem and leads to increasing intractability.

The personal consequences of treatment resistant depression are of continuing morbidity. The patient becomes entrapped in a spiral of hopelessness and helplessness. Their selfesteem is eroded and their ability to live fulfilling lives is diminished; we can only speculate on the internal psychic torment. Failure to respond to treatment will be selfreinforcing. The development of cognitive schema mirroring the patient's day to day functioning is only to be expected, compounding the problem. Helplessness is reinforced as it no longer matters what you think, feel or do.

The most serious risk is of suicide. The link between suicide and depression is almost incontrovertible (Barraclough et al, 1974). Whether any special link exists between treatment resistant depression and suicide rates in excess of that between affective disorder and suicide in general is not clear; one can argue that treatment resistant depressives are at a higher risk, since the length of time that they are unwell is increased, or alternattvely that suicidality diminishes as the patient becomes increasingly intractable. Only a small proportion of depressed patients commit suicide by antidepressant poisoning alone; the use of less toxic drugs would be expected to reduce this, however, there is no clear advantage and it appears that therapeutic fallure is a greater problem than toxicity in the evaluation of antidepressant medication (Isacsson et al, 1994).

The consequences of the patient's continued morbidity are not confined to the patient alone. It affects the family, economy and doctorpatient relationship.

Caring for a sick relative may create an atmosphere of animosity and resentment. If the presence of life stressors are propagating factors, then another vicious circle is established as depression leads to dysfunctional relationships which in turn reinforce the depression. Continuing morbidity affects occupational, social and family roles. These are interlinked and a large variation exists in the burden that the illness causes.

Economic ramifications are potentially very large. If we take an annual incidence of affectlve disorder of (conservattvely) $6 \%$ in women and $3 \%$ in men and that $10 \%$ are treatment resistant, that yields 200000 cases a year. 
Long stay populations do not appear to include them (O'Driscoll et al, 1993), acute inpatient services do not have the capacity to treat them, so 'community care' is provided by family and friends. This economic cost has two components; the consumption of services, and the loss of occupational function with consequent reduction in taxpaying. The former is likely to be the lower cost and is of the order of $\$ 500$ per patient, but is obviously dependent on the duration of the disorder.

The doctor-patient relationship may become distorted, with treatment resistant depresstves 'contained' in general practice. A general practitioner (GP) can expect to acquire an increasing number during his career who come to 'hunt' him (Blacker \& Clare, 1987). The doctor, frustrated by his previous lack of success, views the patient with increasing despair. Therapeutic despair leads to therapeutic inertia and inaction; there may be little inclination to pursue more aggresstve treatments and a tendency to inaction, either by accepting a diagnosis of treatment resistant depression, or by labelling the patient inaccurately on the grounds of prejudice rather than objective criteria. This is used in the diagnosis of personality disorder and the possible abdication of clinical interest. The patient with his problem comes to accept his lot and expect nothing else. Such patients are acceptable in the community and their behaviour, apart from suicide attempts, is unlikely to bring them to psychiatric attention; they have no advocates.

As much as treatment resistant depressives will respond, so many of the consequences personal, social and economic - are avoidable. Most depression is treated in general practice and not in a psychiatric setting. GPs are by their nature generalists and may be unfamiliar with, or lacking confidence in their use of augmentation (Kehoe \& Mander, 1992). They are, however, experts in knowing their patients and their lives.

Psychiatrists are not free from criticism: there is almost certainly a reluctance to treat these patients aggresstvely and a tendency to label them inappropriately.

One hopes that the recognition and management of treatment resistant depression will improve in tandem with the increased awareness of depression in general through the Defeat Depression campaign. It is encouraging that this is being undertaken by both the psychiatric and the medical Royal Colleges. Now that there is a consensus about how the acute illness should be managed, the next step is to define a clear strategy of how to manage those who do not respond. That is the challenge for the future.

\section{References}

BArRaclough, B., BUNCH, J., NerLON, B., et al (1974) A hundred cases of suicide: clinical aspects. British Journal of Psychiatry, 126, 355-373.

BLACKER, C. V. R. \& CLARE, A. W. T. (1989) Depresstve disorder in primary care. Brttish Joumal of Psychiatry. 160, 737-751.

Brown, G. W. \& HARRs, T. (1978) Social Origins of Depression-A Study of Psychiatric Disonders in Women. London: Tavistock.

CorYeu, W., ENDicotT, J. \& Keuer, M. (1990) Outcome of patients with chronic affective disorder. A five year follow-up. American Journal of Psychiatry. 147, 162733.

CoWEn, P. J., McLance, S. L., WARE, C. J., et al (1991) Lithium in tricyclic-resistant depression. Correlation of increased brain 5-HT function with clincical outcome. British Journal of Psychiatry. 189. 341346.

DiNAN, T. G. (1993) Lthium augmentation in sertraline resistant depression: a preliminary dose-response study. Acta Psychiatrica Scandinavica, 88, 300-301.

Isacsson, G., Houmgren, P., Wasserman, D., et al (1994) Use of antddepressants among people committing suicide in Sweden. British Medical Journal, 808 , 506-509.

Jornson, D. A. W. (1991) The significance of depression in schizophrenia from modern trends in the treatment of chronic schisophrenia. Excerpta Medica, 23-34.

JoYCE, P. R. (1994) Predictors for treatment response and treatment selection. Current Opinions in Psychiatry. 7. 26-29.

KEHOE, R. F. \& MANDER, A. J. (1992) Lithium treatment: prescribing and monitoring habits in hospital and general practice. British Medical Journal, s04, 552-554.

KnOH, L., ANDREwS, G. \& NEMSON, M. (1988) The long-term outcome of depresstve illness. Brittsh Journal of Psychlatry, 165, 752-757.

LEE, A. S. \& MURRAY, R. (1988) The long term outcome of Maudsley depresstves. British Joumal of Psychiatry. 163, 741-751.

LEVINE, S. (1986) The management of resistant depression. Acta Psychiatrica Belgica, 86, 141-151.

MANN, A. H., Jenkins, R. \& BeLsey, E. (1981) The twelve month outcome of patients with neurotic illness in general practice. Psychiatric Medictne, 1, 535-550.

Meats, P., TMmol M., Jouney, D. (1991) Prognosis of depression in the elderly. Brttish Joumal of Psychiatry. $169,659-663$.

MinuRD, P. H. (1983) Depression in old age. Brttish Medical Joumal, 287, 375-376.

NeWMaN, R. H. \& Janicak, P. G. (1991) Augmentation strategles in treatment resistant affectlve disorder. Current Opinions in Psychiatry, 4, 65-69.

O'Driscou, C., Wus, W., LerF, J., et al (1993) The TAPS project. 10: the longstay populations of Friern and Claybury hospitals. The baseline survey. British Joumal of Psychiatry, 162 (Suppl. 19), 30-35.

ORMEL, J., OLDEHINKEL, T., BRIMMN, E., et al (1993) Outcome of depression and anxiety in primary care. Archtues of General Psychiatry, 60, 759-766. 
PARKER, G. HOLMER, S. \& MANICAVASAGAR, V. (1986) Depression in general practice attenders - "Caseness", natural history and predictors of outcome. Journal of Affectlue Disorders, 10, $27-35$.

REMiCK, R. A. (1989) Treatment resistant depression. Psychiatric Joumal of the Untwersty of Ottawa, 14. $394-396$.

ScoTt. J. (1992) Are there different subtypes of chronic primary major depression? Preliminary report. Aduances in Affectuve Disonders, 6-7.

ScoTr, J., ECcLeston, D. \& BoYs, R. (1992) Can we predict the persistence of depression? British Journal of Psychiatry, 161, 633-637.

Tennant, C., Bebbington, P. \& HuRRY, J. (1981) The shortterm outcome of neurotic disorders in the communityThe relation of remission to clinical factors and to "neutralizing" life events. British Joumal of Psychiatry. $189,213-220$.

Depression is the commonest psychiatric disorder in the industrialised world. Many patients are now diagnosed and treated with effective antidepressants by primary care physicians. A large proportion of depressed individuals fail to reach their premorbid level of functioning following a course of treatment; estimates vary from $10 \%$ to $30 \%$ (Nierenberg \& Amsterdam, 1990). These individuals require a major input from the services and suffer prolonged distress, with many adverse personal, social and economic consequences.

Kraepelin's division of functional psychosis on the basis of the course of the illness led to the characterisation of depression as a selfremitting disorder. Before the introduction of effective antidepressant treatments, episodes of depression usually lasted 9-12 months (Kraepelin, 1913). Depression that did not respond to the avallable management strategles was considered a 'character neurosis' or 'depressive personality'. The introduction of tricyclic antidepressants added to the optimistic view of depression as an episodic and treatable disorder. In the last few decades, increasing evidence has accumulated that depression can, and often does, become treatment resistant and chronic, with consequent high morbidity and mortality (Keller et al, 1984; Lee \& Murray, 1988).

\section{Definition}

The term 'treatment resistant depression' pressumes that there is an agreed and widely shared range or combination of treatments that are used in a standardised way for
Whokur, G., Corrsu, W., Krular, M., et al (1993) A prospective follow-up of patients with bipolar and prtmary unipolar affec-tive disorder. Archives of General Psychiatry, 60, 457-465.

*Andrew J. Smith, Registrar in Psychiatry, West London Healthcare Trust, Uxbridge Road, Southall, Middlesex UB1 3EU

"Correspondence: Park House, Nursery Road, Huntingdon, Cambs PE18 6RJ

treating depression. In practice, treatment strategles vary widely. General practitioners prefer to use low, sometimes inadequate doses of older drugs, or the newer, less toxic compounds. In the absence of research-based guidelines, psychiatrists devise treatment plans based upon personal experience and anecdotal evidence, with differing emphasis upon other treatment options such as psychotherapy. Research definitions for resistant depression also vary widely (Nierenberg \& Amsterdam, 1990).

One simple and clinically useful definition of resistant depression is a fallure of response to an adequate trial of antidepressant treatment (Nelson \& Dunner, 1993). In 1974, the World Psychiatric Association proposed that treatment resistance should be divided into absolute resistance and relattve resistance. Absolute resistance was defined as a failure of one adequate antidepressant trial specified as four weeks of $150 \mathrm{mg} /$ day of imipramine or its equivalent. A poor response to an inadequate course of treatment was called relative resistance. This distinction emphasises the need for an adequate trial of antidepressants before a patient is considered treatment resistant.

\section{Causes}

The lack of consensus on the definition, phenomenology, and the causation of resistant depression has made it largely "a labelling phenomenon... Patients have refractory depression because they have been labelled as such" (Guscott \& Grof, 1991). The label 